Okasha, A. (2008) Would the use of dimensions instead of categories remove problems related to subthreshold disorders? European Archives of Psychiatry and Clinical Neuroscience, 259, 129-133.

Regier, D. A., Narrow, W. E., Kuhl, E. A., et al (2009) The conceptual development of DSM-V. American Journal of Psychiatry, 166, 645-650.
Shankman, S. A., Klein, D. N., Lewinsohn, P. M., et al (2008) Family study of subthreshold psychopathology in a community sample. Psychological Medicine, 38, 187-198.

Zlotnik, C., Franklin, C. L. \& Zimmerman, M. (2002) Does subthreshold posttraumatic stress disorder have any clinical significance? Comprehensive Psychiatry, 43, 413-419.

\title{
Children caught up in conflict
}

\author{
David Skuse
}

Behavioural and Brain Sciences Unit, Institute of Child Health, London, UK, email dskuse@ich.ucl.ac.uk

W e present our theme in this issue with an emphasis on the Middle East. Unrest between Israel and Palestine has a long history. Even when there is no overt aggression by either side, decades of conflict may have engendered cognitive distortions and emotional vulnerability.

Danny Brom and colleagues emphasise that there is evidence that even infants and pre-school children in Israel have suffered the consequences of trauma, or anticipated trauma. Their reactions look very much like the post-traumatic stress disorder (PTSD) we see after exposure to a variety of abusive experiences. Up to one-third of children who have been living in areas that are subject to missile attacks in Israel show some symptoms of PTSD. It seems that the duration of exposure to threats of potential violence is a particularly important variable. Similar patterns of disturbance have been observed in older children and adolescents. Interventions based within schools, from early childhood through to adolescence, have been shown to have measurable benefits.

In the Palestinian territory of Gaza, Abdel Aziz Thabet and colleagues describe the evidence for psychiatric disorders following exposure to war during middle childhood and adolescence. The Gaza territory has suffered major structural damage to domestic property in recent years as a consequence of Israeli incursions. The authors were particularly interested in the possibility that components of attention-deficit hyperactivity disorder (as well as PTSD) could be related to exposure to such events. Using a variety of standardised instruments, the team surveyed a representative sample of children from cities, villages and refugee camps. Over a third were found to have experienced at least some PTSD symptoms.

In the third of our thematic papers on the longer-term impact of conflict on children, we revisit the Rwandan genocide. Ian Palmer and Nsanzumuhire Firmin describe the outcomes for children who had been caught up in the terrible events of 1994. They are now in early adulthood. The nature and scale of the depraved behaviour that occurred throughout Rwandan society was probably without precedent in modern times, in terms of both the proportion of the population affected and the involvement of children themselves as perpetrators as well as victims of the violence. Attempts at restorative justice have seemingly not proved very effective in this, Africa's most densely populated country. Half the population was born after the conflict; many children were the product of rape. Many more have HIV/AIDS. Attempts are being made to establish an effective mental health service in Rwanda, but progress is slow.

\section{President's Medals}

During its 2011 International Congress, the College celebrated the achievements and contributions to mental health from people in all walks of life by presenting them with President's Medals. There were nine medal winners this year:

\footnotetext{
- Dr Martin Deahl

- Dr Andrew McCulloch

- Ms Trisha Goddard

- Dr Peter Hughes

- Dr E. S. Krishnamoorthy

- Norman Lamb MP

- Emma Thompson

- Dr Peter Carter

- HE Kjell Magne Bondevik
}

Further information about these medal winners is available on the College website (http://www.rcpsych.ac.uk). 